\title{
Bridge Deck Load Testing Using Sensors and Optical Survey Equipment
}

\author{
Hubo Cai, ${ }^{1}$ Osama Abudayyeh, ${ }^{2}$ Ikhlas Abdel-Qader, ${ }^{3}$ Upul Attanayake, ${ }^{2}$ \\ Joseph Barbera, ${ }^{2}$ and Eyad Almaita ${ }^{3}$
}

${ }^{1}$ Division of Construction Engineering and Management, School of Civil Engineering, Purdue University, 550 Stadium Mall Drive,
West Lafayette, IN 47907, USA
${ }^{2}$ Department of Civil and Construction Engineering, Western Michigan University, Kalamazoo, MI 49008, USA
${ }^{3}$ Department of Electrical and Computer Engineering, Western Michigan University, Kalamazoo, MI 49009, USA

Correspondence should be addressed to Hubo Cai, hubocai@purdue.edu

Received 8 August 2011; Accepted 23 October 2011

Academic Editor: Polat Gülkan

Copyright ( $\odot 2012$ Hubo Cai et al. This is an open access article distributed under the Creative Commons Attribution License, which permits unrestricted use, distribution, and reproduction in any medium, provided the original work is properly cited.

\begin{abstract}
Bridges are under various loads and environmental impacts that cause them to lose their structural integrity. A significant number of bridges in US are either structurally deficient or functionally obsolete, requiring immediate attention. Nondestructive load testing is an effective approach to measure the structural response of a bridge under various loading conditions and to determine its structural integrity. This paper presents a load-test study that evaluated the response of a prefabricated bridge with full-depth precast deck panels in Michigan. This load-test program integrates optical surveying systems, a sensor network embedded in bridge decks, and surface deflection analysis. Its major contribution lies in the exploration of an embedded sensor network that was installed initially for long-term bridge monitoring in bridge load testing. Among a number of lessons learned, it is concluded that embedded sensor network has a great potential of providing an efficient and accurate approach for obtaining real-time equivalent static stresses under varying loading scenarios.
\end{abstract}

\section{Introduction}

Bridges are a critical component of a nation's ground transportation infrastructure system that allows the movement of people and goods from one place to another. Bridges are exposed to load effects and weather impacts that lead to their deterioration. Federal Highway Administration (FHWA) statistics show that about $20 \%$ of the National Highway System (NHS) bridges and $27 \%$ of non-NHS bridges in US are either structurally deficient or functionally obsolete [1], resulting in a total of about 152,000 bridges requiring immediate attention in the form of repair or replacement. Therefore, routine inspection and load testing are needed to obtain good estimates on bridge response and to support making decisions of appropriate maintenance and rehabilitation activities to ensure their structural integrity and safety $[2,3]$.

A recent trend in bridge management is the utilization of sensors embedded in the bridge structure to monitor the long-term performance of bridges, under various loads and environmental impacts. Given the monitored data, meaningful information regarding the bridge reliability can be extracted [4]. This is particularly true with the growing adoption of the prefabrication technology in bridge construction. This technology allows the prefabrication of structural components to be conducted offsite under a well-controlled environment with the benefit of higherquality precast structural components that are expected to perform better with lower maintenance needs, compared to conventional cast-in-place concrete bridges [5]. By reducing the onsite construction time, this prefabrication technology can also save construction time and minimize traffic disruption [6]. Due to its relatively short history in bridge construction, long-term performance data of prefabricated bridges are rarely existent, and sensor technology is many times utilized to monitor their long-term performance. This scenario of embedding sensors in bridge structure is also the case with the Parkview Bridge in Kalamazoo, Michigan, which was constructed in 2006 as a totally 
prefabricated system. Vibrating-wire strain gages (sensors) were embedded in the precast deck panels to form a sensor network for continuous health monitoring and condition assessment.

While the original intention of embedding sensors into bridges is to continuously monitor their long-term performance, these sensors may serve as an alternative method for measuring the structural response of a bridge under nondestructive load testing. This paper presents the results of a load testing study to evaluate the response of the Parkview Bridge under varying load configurations via nondestructive load testing and the utilization of an embedded sensor network. In this study, a load testing method that incorporates optical surveying systems, the embedded sensor network, and deflection analysis was designed and implemented. The major contribution of this study is its demonstration of how an embedded sensor network might be utilized to acquire real-time equivalent static stresses under various loading scenarios.

\section{Bridge Load Testing}

The actual response of a bridge to loads is usually better than what the theory dictates [7]. Factors that contribute to the load capacity difference include unintended composite action, load distribution effects, participation of parapets, railings, curbs, and utilities, material property differences, unintended continuity, participation of secondary members, effects of skew, portion of load carried by deck, and unintended arching action due to frozen bearings [7].

Load testing is recommended by AASHTO [8] as an "effective means of evaluating the structural response of a bridge." The purpose of conducting load testing on existing bridges is to evaluate their structural response without causing damages. Therefore, load testing is usually conducted in a nondestructive manner and is sometimes referred to as nondestructive load testing. The goal of this type of testing is to compare field response of the bridge under test loads with its theoretical response [7]. Nondestructive load testing can be further categorized into diagnostic testing and proof testing. Diagnostic testing methods provide the measurements necessary to analyze differential loading effects (i.e., moment, shear, axial force, deflection, etc.) present in various structural members due to applied loads [9]. Proof-load testing aims at determining the magnitude and configuration of loads that cause critical structural components to approach their elastic limit.

Tasks involved in a program of load testing typically include the determination of testing objectives and load configuration, the selection and placement of instrumentation, the adoption of appropriate analysis techniques, and the evaluation and comparison of test results and analytical results [10]. Load testing is being carried out widely to evaluate and rate bridge response on a case-by-case manner to evaluate new construction materials and technologies $[10,11]$. While a number of bridge load testing studies can be found in the literature, such studies on bridges using embedded sensors, which is the focus of this paper, are almost nonexistent.

\section{Bridge under Test: Parkview Bridge}

The Parkview Bridge is located in Kalamazoo, MI. The 249foot long bridge over US-131 is particularly relevant concerning the advancement of both bridge construction technology and structural monitoring. Being the first of its kind in Michigan, the concrete superstructure of the Parkview Bridge is almost entirely precast, including girders and deck panels. The substructure also has precast concrete piers. This configuration allowed for the implementation of rapid bridge construction (RBC) technology. A second feature of the structure is a network of sensors that was embedded in the deck panels during casting. This sensor network will continuously monitor the response of the bridge to various loads and environmental effects (temperature changes).

The Parkview Bridge consists of four spans, which from east to west are approximately 38, 83, 83, and 45 feet, respectively. The three lanes of traffic are supported by seven precast prestressed AASHTO type III girders spaced at $8^{\prime} 7^{\prime \prime}$. Figure 1(a) provides a cross-sectional view of the bridge to illustrate the girder spacing and the deck-panel dimensions. The bridge deck comprises 48 precast nonprestressed 9-inch thick deck panels, skewed at 23 degrees and posttensioned longitudinally; see Figure 1(b). The sensors within the deck panels are placed at varying locations and orientations with the objective of measuring all relevant stresses that are predicted to develop in the bridge deck. Figure 2 illustrates the locations and orientations of the sensors embedded in the bridge deck panels.

\section{Load Testing Design and Implementation Methodology}

This section describes the objectives, approaches, testing scenarios, load configurations, and testing procedures related to the design and implementation of the load testing program.

4.1. Load Testing Objectives and Approaches. The overall goal of conducting load tests on the Parkview Bridge is to quantify its response to various loading conditions. Specific objectives include measuring roadway-surface deflections due to various live loads, deriving stresses from measured deflections via analytical models, and comparing analytical results with results derived from sensor readings.

Figure 3 presents a flow chart that describes the approaches and tasks used to carry out the testing. The first task is to determine load configurations that should produce the maximum moments in the bridge girders and the maximum deflections of the bridge deck surface. The next step is to compute stresses using calculated girder deck composite-section properties and measured deflections. Roadway-surface deflections are measured by optical surveying using a Trimble Dini level with a precision of 0.0012 inch $(0.003048 \mathrm{~cm})$. Stresses derived from measured deflections are compared to stresses derived from sensor strain readings for verification and further analysis.

4.2. Testing Scenarios. A total of ten load scenarios, including four single directional (one truck) and six bidirectional (two 


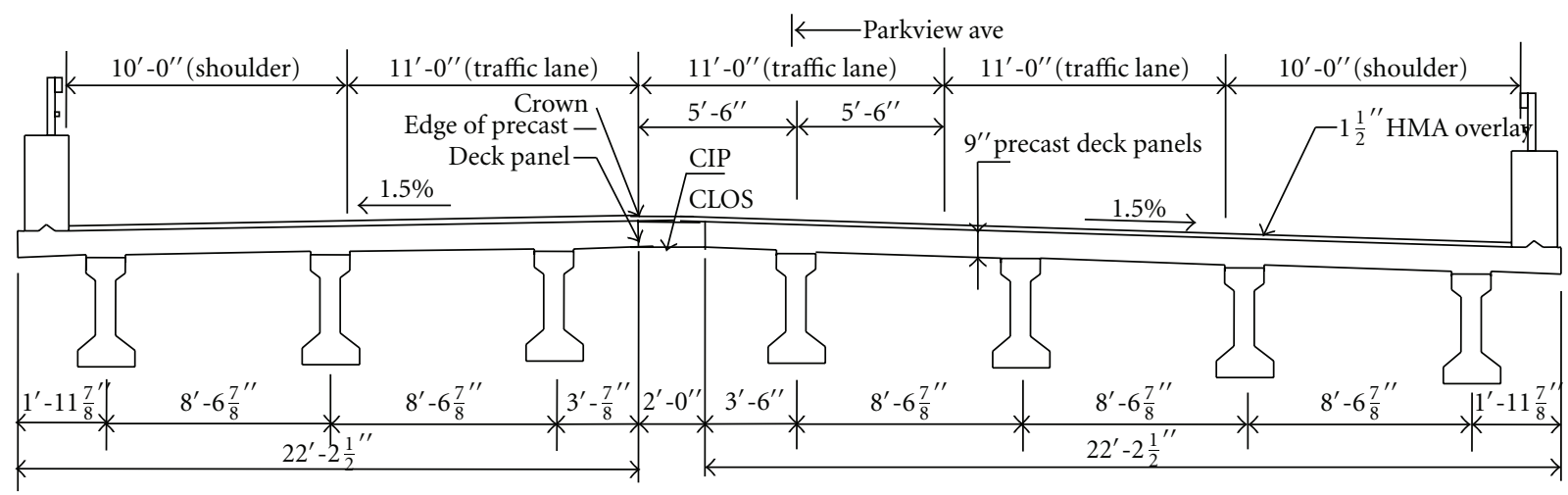

(a) Cross-sectional view of the Parkview Bridge

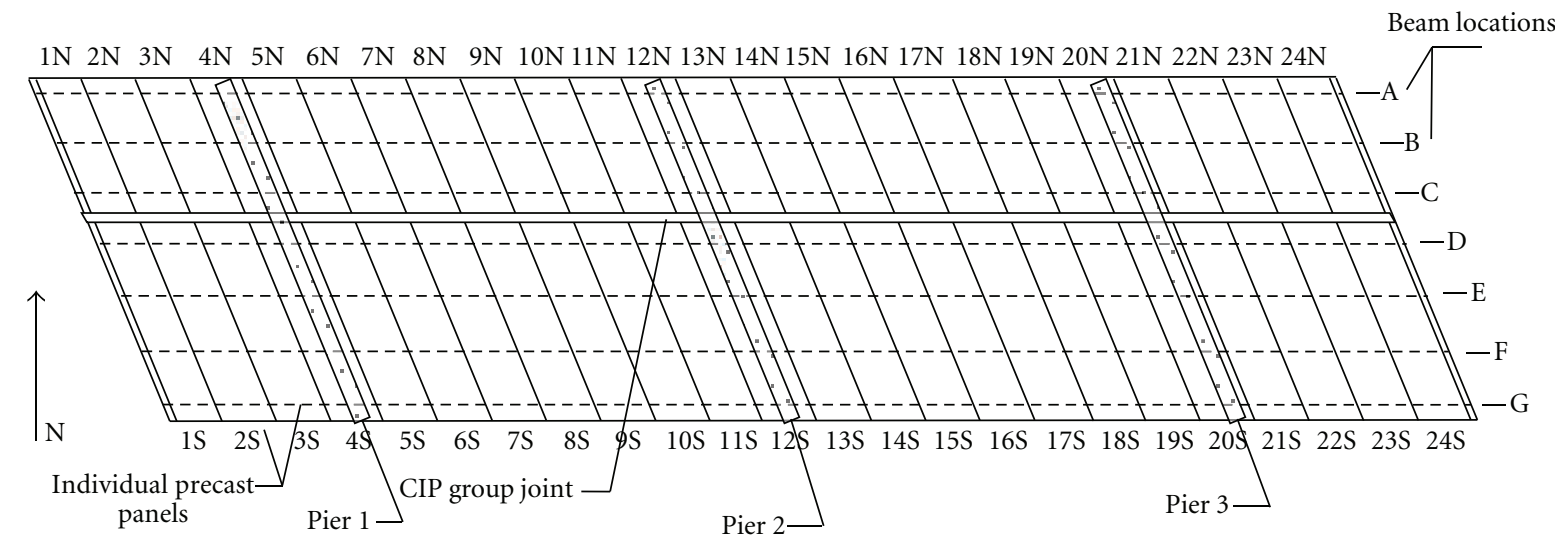

(b) Deck-panel plan view

Figure 1: Parkview bridge schematic.

TABLE 1: Testing scenarios.

\begin{tabular}{lcc}
\hline Scenarios & $\begin{array}{c}\text { Truck location } \\
\text { (single direction-1 truck) }\end{array}$ & $\begin{array}{c}\text { Truck location } \\
\text { (bidirectional-2 trucks) }\end{array}$ \\
\hline 1 & 47 & - \\
2 & 42 & - \\
3 & 49 & - \\
4 & 40 & - \\
5 & - & 45,44 \\
6 & - & 47,42 \\
7 & - & 49,40 \\
8 & - & 51,38 \\
9 & - & 47,40 \\
10 & - & 45,38 \\
\hline
\end{tabular}

trucks with opposite heading directions), were designed and implemented in this study. Figure 4 illustrates the midspan locations, where the test loads were placed. Table 1 lists the testing scenarios with their load locations. Before the load testing, roadway surface elevations at these midspan locations, and also at locations above the bridge piers (represented by triangles), were measured before the loads were in place to provide a surface baseline. During the load tests, when the loads were in place, surface elevations at these locations were measured again to determine surface deflections due to specific test loads.

4.3. Load Configuration. Two types of trucks were used to provide test loads. Figure 5 illustrates the configuration of the trucks used for the single-directional and the bidirectional testing. In this study, single-directional testing means using only one truck, while bidirectional testing means using two trucks simultaneous and when these two trucks were driven to their intended locations facing each other. These configurations were chosen to closely match two trucks that are included in Michigan's set of legal truck-load configurations. The type I truck illustrated in Figure 5 was chosen to approximately match the HS20 design truck used in the design of the bridge. Table 2 provides the measured axle weights for all three trucks (one type I truck and two type II trucks) used in this study.

\subsection{Load Testing Procedure. The steps below were followed.}

Step 1. Load trucks to approximate AASHTO HS20 and legal Michigan truck configuration and utilize truck weigh stations to determine actual axle weights.

Step 2. Based upon actual axle weight, mark a point on each truck in such a way that when this point is aligned with 


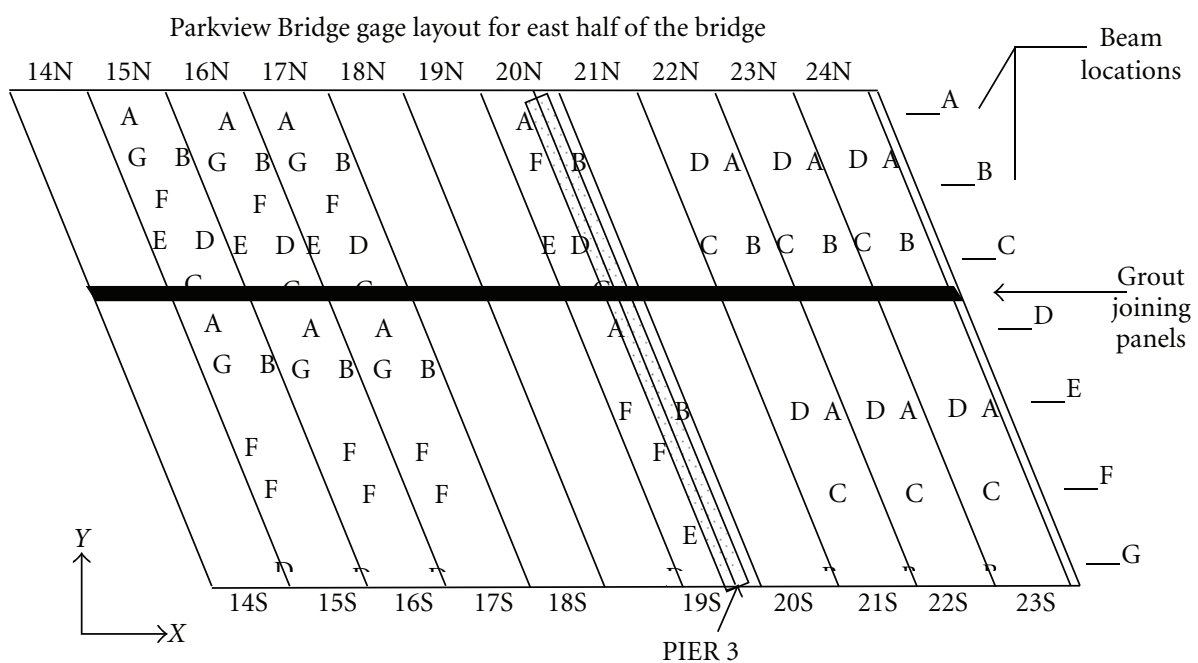

(a) East half

Parkview Bridge gage layout for west half of the bridge

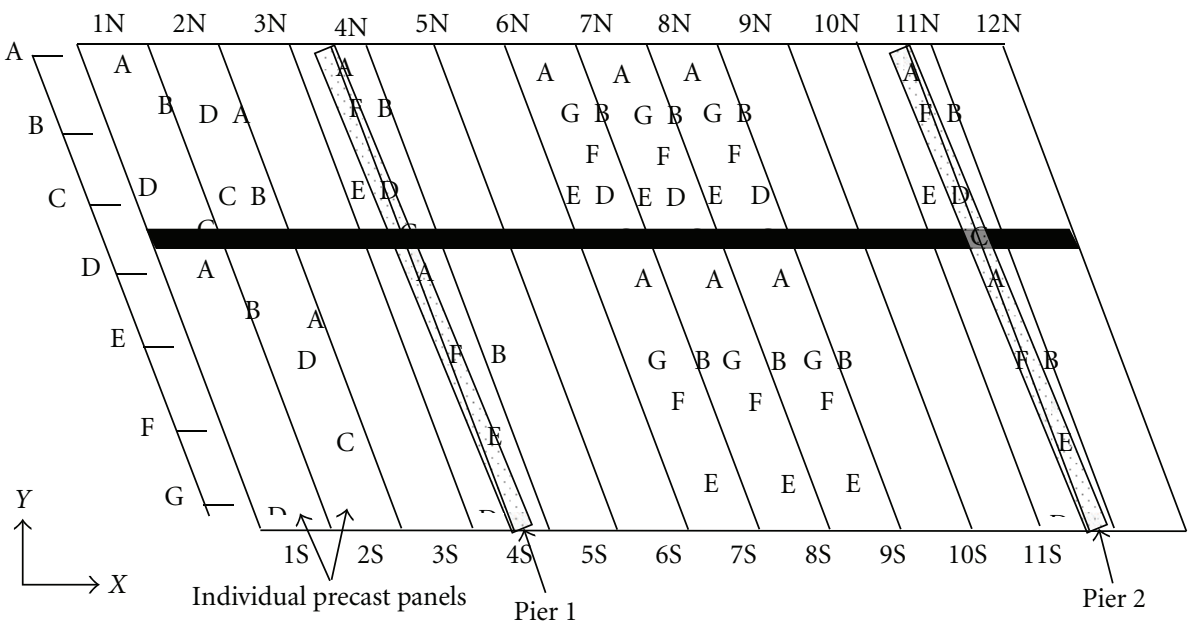

(b) West half

Figure 2: Gage layout and orientation for the Parkview Bridge.

TABLE 2: Actual loaded truck weights.

Loaded truck weight configurations

\begin{tabular}{lccc} 
Axle no. & Single directional truck type 1 weights (pounds*) & Bidirectional truck type 2 weights (pounds*) \\
\hline Front axle & 9,640 & 17,850 & 18,350 \\
No. 2 axle & 35,540 & 18,050 & 18,600 \\
No. 3 axle & & 17,800 & 18,250 \\
No. 4 axle & 34,580 & - & - \\
No. 5 axle & 79,760 & 53,700 & 55,200 \\
\hline Gross weight & & - & - \\
\hline
\end{tabular}

${ }^{*} 1$ pound of mass $=0.4536 \mathrm{~kg} ; 1$ pound of force $=4.4482 \mathrm{~N}$.

midspan locations of deck panels, the truck load causes the maximum moment in deck panels.

Step 3. While the trucks are being loaded prior to testing, the survey crew sets up and determines girder midspan locations and pier centerline locations as shown in Figure 4. These locations are marked for future alignment of truck marks and midspan locations in Step 5.

Step 4. Measure surface elevations of points illustrated in Figure 4 to establish a baseline for testing scenario 1. 


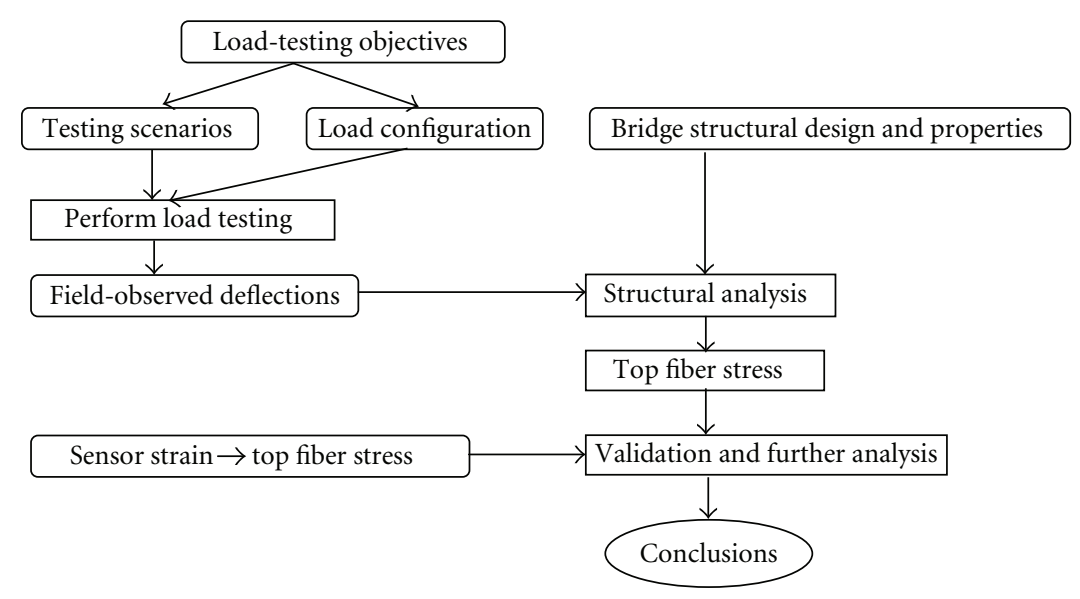

FIGURE 3: Flow chart of the bridge load testing.

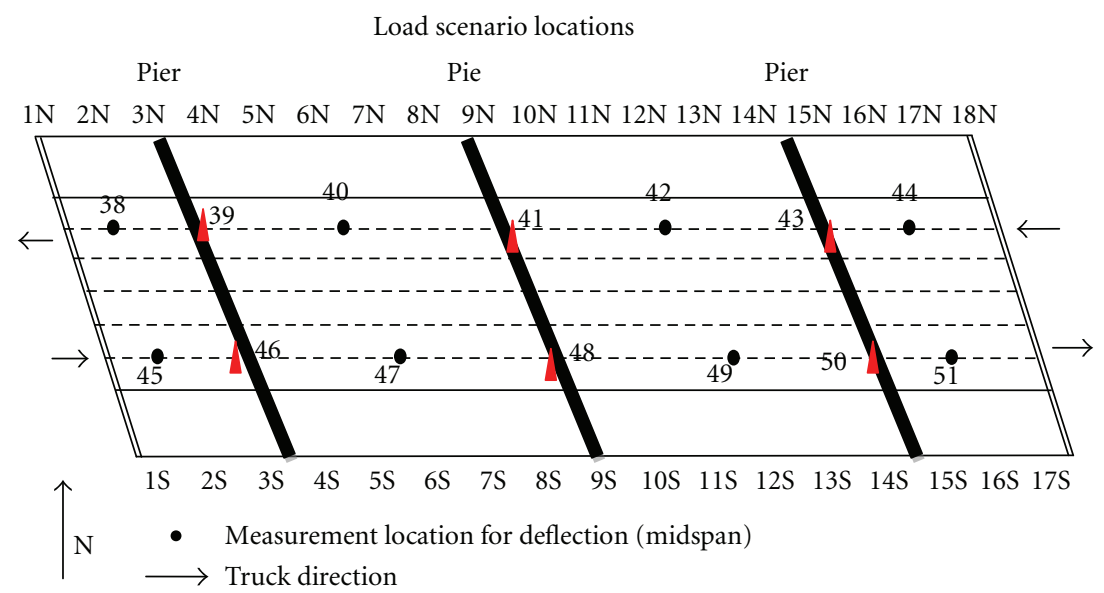

Figure 4: Load locations.

Step 5. Move type I truck to point 47 in Figure 4 (scenario 1). After the truck is in place, measure surface elevations to determine bridge deflection due to the truck load.

Step 6. Record the time the truck is in position and ensure that the truck stays in position for a minimum of 10 minutes to allow the sensors to register their readings (sensors collect data at 5 -second increments during the 10 -minute time period, and these readings were averaged).

Step 7. Move the truck off the bridge.

Step 8. Repeat Steps 4 to 7 for the remaining testing scenarios.

4.5. Control of Temperature Variations. It is well recognized that environmental factors, particularly temperature variations, can lead to large strains, and when the structure is restrained as in bridges, they can cause large stresses, even though the wire strain gages are self-temperature compensating. Considering the extreme weather conditions that are common in Michigan during winter, load testing studies shall at least plan for temperature variations. In this load testing study, the original plan of controlling the effects of temperature variation was to start the testing in the morning and monitor the ambient temperature, and when it falls out of the $5^{\circ}$ range, the testing pauses and resumes either later that day when the temperature cools down or next morning. In reality, it rained on the day of testing, and the temperature variation was a way below the $5^{\circ}$ range to allow all the 10 scenarios to be tested on a single day.

\section{Load Testing Results}

The load-test program was performed twice: first in September 2008 before the bridge was opened to traffic and again in June 2009. During the first load test, the sensor network was not yet operational. During the second load test, the sensor network was functional and was used in the load test of the bridge. This section presents the results from the second load test only.

Table 3 summarizes surface deflections measured in the field during the second load testing, under the ten loading scenarios. 


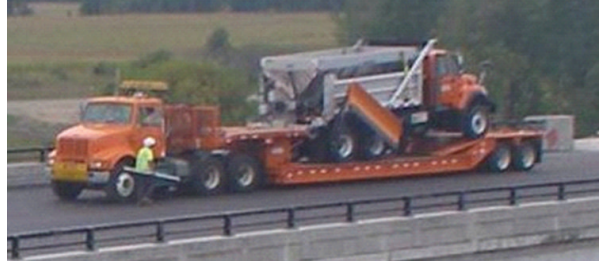

Type I truck for single-directional testing

(a)

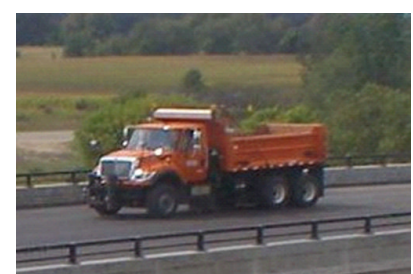

Type II truck for bidirectional testing

(b)

Figure 5: General configurations of trucks.

TABLE 3: Measured surface deflections.

\begin{tabular}{|c|c|c|c|c|c|c|c|c|c|c|}
\hline \multirow{2}{*}{ Location } & \multicolumn{10}{|c|}{ Surface deflections in 10 scenarios (inches*) } \\
\hline & 1 & 2 & 3 & 4 & 5 & 6 & 7 & 8 & 9 & 10 \\
\hline 38 & 0.01 & 0.05 & -0.05 & 0.04 & 0.01 & 0.00 & 0.01 & -0.06 & 0.00 & -0.05 \\
\hline 39 & 0.01 & -0.04 & -0.02 & 0.02 & 0.02 & -0.01 & -0.02 & 0.00 & 0.00 & -0.01 \\
\hline 40 & 0.00 & -0.05 & -0.02 & -0.04 & 0.00 & -0.01 & -0.06 & 0.01 & -0.07 & 0.02 \\
\hline 41 & 0.02 & -0.02 & -0.04 & -0.03 & 0.00 & 0.00 & -0.02 & 0.00 & 0.00 & -0.01 \\
\hline 42 & 0.00 & -0.09 & -0.02 & 0.04 & 0.01 & -0.07 & -0.01 & 0.02 & 0.02 & 0.00 \\
\hline 43 & 0.00 & -0.02 & -0.03 & 0.01 & 0.04 & -0.01 & 0.00 & 0.01 & 0.01 & -0.01 \\
\hline 44 & -0.02 & -0.01 & -0.03 & 0.00 & -0.03 & 0.00 & 0.01 & 0.01 & 0.00 & 0.01 \\
\hline 45 & 0.01 & -0.05 & -0.04 & 0.02 & 0.02 & 0.00 & 0.00 & -0.02 & 0.01 & -0.02 \\
\hline 46 & 0.10 & -0.02 & -0.04 & 0.04 & 0.01 & 0.02 & -0.01 & -0.01 & 0.02 & 0.21 \\
\hline 47 & -0.04 & -0.04 & -0.02 & 0.01 & -0.01 & -0.07 & 0.00 & 0.02 & -0.06 & 0.01 \\
\hline 48 & 0.02 & -0.01 & -0.05 & 0.00 & -0.02 & 0.00 & 0.02 & 0.01 & -0.02 & 0.00 \\
\hline 49 & 0.01 & -0.01 & -0.07 & 0.01 & -0.01 & 0.01 & -0.04 & 0.03 & -0.01 & 0.00 \\
\hline 50 & 0.00 & -0.01 & -0.03 & -0.01 & -0.02 & -0.02 & 0.01 & 0.01 & 0.00 & 0.00 \\
\hline 51 & -0.02 & -0.01 & 0.00 & -0.02 & 0.00 & 0.01 & 0.00 & -0.01 & -0.01 & 0.01 \\
\hline
\end{tabular}

${ }^{*} 1$ inch $=2.54 \mathrm{~cm}$.

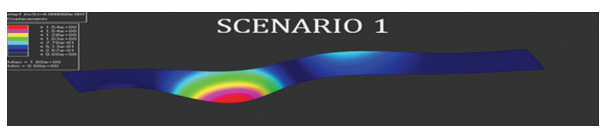

(a) Simulated deflected shape

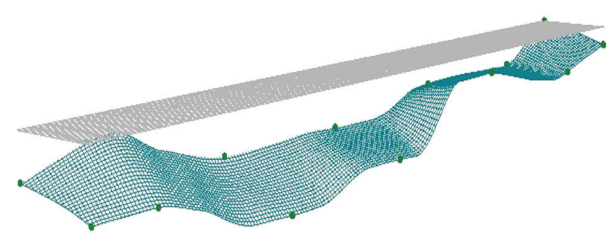

(b) Actual deflected shape

Figure 6: Validating scenario 1 results (not drawn to scale).

5.1. Field Measurements Validation. Three-dimensional plots of surface-deflection measurements were developed and compared with the finite element (FE) simulation results. Figure 6 illustrates the comparison for testing scenario 1 . The deflected shape of the surface obtained from field observations matchs the deflected shape from analytical results, providing confidence in the measurements from testing scenario 1 observations. Similar comparisons were conducted to validate results in all the 10 testing scenarios.
5.2. Top Fiber Live Load Stresses from Deflection Measurements. After validating field observations, moments were derived from surface deflections, and top fiber stresses were calculated utilizing the two PCI equations below and using the simply supported moments at midspans (i.e., assuming zero moments at the piers for conservative results at midspans) [12]. The moments at the piers were then computed from the mid span moments using distribution factors obtained from simulated, unit-force loadings that mimic the truck loads from the 10 scenarios,

$$
\begin{aligned}
M_{\mathrm{LL}} & =D\left(\frac{48 E I_{c}}{5 L^{2}}\right), \\
\sigma_{\mathrm{LL}} & =\frac{M_{\mathrm{LL}} y}{I_{c}},
\end{aligned}
$$

where $M_{\mathrm{LL}}$ : live load moment; $D$ : deflection (inches); $E$ : section modulus of elasticity $(4,600,000 \mathrm{psi}) ; I_{c}$ : moment of inertia of composite section $\left(438,913\right.$ in $\left.^{4}\right) ; M_{\mathrm{LL}}$ : moment (lb-in); $L$ : span length (inches); $y$ : distance from the top fiber to the neutral axis (18 inches); $\sigma_{\mathrm{LL}}$ : stress (psi).

The live-load stress results derived from deflection measurements are presented in Tables 4 and 5 (negative values indicate compression). 
TABLE 4: Live load stresses from deflections (analytical)—south side panels (psi*).

\begin{tabular}{|c|c|c|c|c|c|c|c|}
\hline Scenarios & Midspan (45) & Pier 1 (46) & Midspan (47) & Pier 2 (48) & Midspan (49) & Pier 3 (50) & Midspan (51) \\
\hline Scenario 1 & 47 & 40 & -34 & 12 & 10 & -9 & -50 \\
\hline Scenario 2 & -186 & -159 & -29 & -10 & -11 & -10 & -17 \\
\hline Scenario 3 & -140 & -119 & -19 & -7 & -57 & -55 & -7 \\
\hline Scenario 4 & 93 & 80 & 6 & 2 & 6 & -6 & -63 \\
\hline Scenario 5 & 70 & 60 & -7 & -2 & -6 & -6 & -10 \\
\hline Scenario 6 & 0 & 0 & -58 & 21 & 5 & -5 & 33 \\
\hline Scenario 7 & 0 & 0 & 0 & 0 & -35 & 34 & -3 \\
\hline Scenario 8 & -93 & -80 & 14 & 5 & 20 & 19 & -30 \\
\hline Scenario 9 & 47 & 40 & -51 & -19 & -8 & -7 & -23 \\
\hline Scenario 10 & -96 & 82 & 9 & -3 & -2 & 2 & 36 \\
\hline
\end{tabular}

${ }^{*} 1 \mathrm{psi}=6,895 \mathrm{kPa}$.

TABLE 5: Live load stresses from deflections (analytical)—north side panels (psi*).

\begin{tabular}{|c|c|c|c|c|c|c|c|}
\hline Scenarios & Midspan (38) & Pier 1 (39) & Midspan (40) & Pier $2(41)$ & Midspan (42) & Pier 3 (43) & Midspan (44) \\
\hline Scenario 1 & 47 & 0 & 0 & 0 & 0 & -57 & -66 \\
\hline Scenario 2 & 186 & -37 & -38 & -25 & -68 & -23 & -27 \\
\hline Scenario 3 & -186 & -18 & -19 & -5 & -12 & -60 & -70 \\
\hline Scenario 4 & 140 & 27 & -28 & -13 & 35 & 9 & 10 \\
\hline Scenario 5 & 47 & 4 & -4 & -2 & 5 & 81 & -95 \\
\hline Scenario 6 & 0 & -9 & -10 & 21 & -58 & -9 & 10 \\
\hline Scenario 7 & 47 & -5 & -5 & -4 & -12 & 31 & 36 \\
\hline Scenario 8 & -233 & 6 & 7 & -7 & 19 & 23 & 27 \\
\hline Scenario 9 & 0 & 57 & -59 & 4 & 10 & 9 & -10 \\
\hline Scenario 10 & -143 & -15 & 15 & -1 & -3 & -20 & 23 \\
\hline
\end{tabular}

${ }^{*} 1 \mathrm{psi}=6,895 \mathrm{kPa}$.

5.3. Top Fiber Live Load Stresses from Sensor Readings. During the load testing, top fiber strains were recorded by the embedded sensors in the bridge deck panels and downloaded to the laboratory computer for analysis. Even though the sensors are installed throughout the entire bridge deck, only those sensors located along the longitudinal load path were used to derive live load stresses and to compare them to the stresses derived from deflections. Tables 6 and 7 present the stresses derived from the sensors for the south-side and the north-side panels, respectively (negative values indicate compression).

5.4. Total Stresses. Live load stresses are added to dead load stresses calculated based upon structural design and material properties of this bridge to obtain the total top fiber stresses, which are then compared to the allowable compression and tension stresses to ensure that the structure is within design limits under varying loading scenarios. In calculating stresses from load test deflections, we conservatively assumed simply supported span moments as follows:

$$
\begin{aligned}
\sigma_{\mathrm{LL}} & =\frac{M_{\mathrm{LL}} y}{I_{c}}, \\
M_{\mathrm{LL}} & =D\left(\frac{48 E I_{c}}{5 L^{2}}\right),
\end{aligned}
$$

where $M_{\mathrm{LL}}$ : live load moment (lb-in); $D$ : deflection (inches); $E$ : section modulus of elasticity $(4,600,000 \mathrm{psi}) ; \mathrm{I}$ : moment of inertia of composite section $\left(438,913 \mathrm{in}^{4}\right) ; \mathrm{L}$ : span length (inches); $y$ : distance from the top fiber to the neutral axis (18 in); $\sigma_{\mathrm{LL}}$ : stress (psi).

The average 28-day compression strength $\left(f^{\prime} c\right)$ was recorded as approximately $8,000 \mathrm{psi}$ from concrete samples taken during the casting. Therefore, maximum allowable stresses in the concrete are as follows:

$$
\begin{gathered}
\text { compression }(f c): \quad f c \leq 0.45 f^{\prime} c \Longrightarrow 3,600 \text { psi, } \\
\text { tension }(f t): \quad f t \leq 6 \sqrt{f^{\prime} c} \Longrightarrow 537 \text { psi. }
\end{gathered}
$$

Table 8 provides the deck dead-load stresses that are combined with the live-load stresses given in Tables 4 through 7 to compute total stresses presented in Tables $9,10,11$, and 12 for all scenarios using the deflection measurements and sensor-readings methods. It is clear from these tables that the total stresses are within the allowable limits for all testing scenarios for both the south and north panels.

\section{Discussions and Concluding Remarks}

Overall, the load tests were effective in providing information about the bridge's structural response. Stresses in all of the 
TABLE 6: Live load stresses from sensors—-south side panels (psi*).

\begin{tabular}{|c|c|c|c|c|c|c|c|}
\hline Scenarios & Midspan (45) & Pier 1 (46) & Midspan (47) & Pier 2 (48) & Midspan (49) & Pier 3 (50) & Midspan (51) \\
\hline Scenario 1 & 1.48 & 10.60 & -11.68 & 6.52 & 5.38 & -6.82 & -0.33 \\
\hline Scenario 2 & 0.80 & -1.50 & 2.52 & 1.00 & 9.57 & -14.05 & 0.45 \\
\hline Scenario 3 & 1.55 & 0.65 & 2.48 & 11.77 & -24.14 & 8.97 & 2.80 \\
\hline Scenario 4 & 3.00 & 11.70 & -2.43 & 11.95 & 2.75 & -0.65 & -0.20 \\
\hline Scenario 5 & -2.80 & -2.05 & 0.28 & -0.20 & -0.27 & -0.55 & -0.15 \\
\hline Scenario 6 & -0.40 & 6.30 & -13.50 & 22.10 & -3.65 & 11.30 & -0.15 \\
\hline Scenario 7 & 0.93 & -0.28 & -0.69 & 11.30 & -30.68 & 4.72 & 1.18 \\
\hline Scenario 8 & -5.95 & 0.00 & 0.85 & -0.55 & 0.93 & 3.35 & 2.65 \\
\hline Scenario 9 & 3.50 & -2.00 & 15.63 & -21.35 & -5.12 & 3.70 & -1.60 \\
\hline Scenario 10 & -8.55 & -2.40 & 0.20 & 0.25 & 1.38 & -0.55 & 0.05 \\
\hline
\end{tabular}

${ }^{*} 1 \mathrm{psi}=6,895 \mathrm{kPa}$.

TABLE 7: Live load stresses from sensors—north side panels (psi*).

\begin{tabular}{lccccccc}
\hline Scenarios & Midspan (38) & Pier 1 (39) & Midspan (40) & Pier 2 (41) & Midspan (42) & Pier 3 (43) & Midspan (44) \\
\hline Scenario 1 & 1.60 & 8.85 & -8.88 & 4.55 & 5.47 & -0.87 & -0.10 \\
Scenario 2 & 1.95 & -1.95 & 2.32 & 1.45 & 14.63 & 0.40 \\
Scenario 3 & 1.95 & 0.70 & 3.82 & 10.63 & -11.06 & 4.93 & 4.02 \\
Scenario 4 & 3.95 & 18.75 & -26.33 & 17.75 & 3.53 & 0.25 & 0.50 \\
Scenario 5 & -2.75 & -1.30 & -0.10 & -0.65 & 0.65 & 0.10 & 0.15 \\
Scenario 6 & -0.15 & 4.45 & -6.53 & 21.90 & -25.93 & -3.50 & 0.02 \\
Scenario 7 & 1.55 & 5.45 & -10.87 & 11.82 & -3.51 & -2.65 & 2.70 \\
Scenario 8 & -6.05 & 0.35 & -0.60 & -0.95 & -0.92 & -10 \\
Scenario 9 & 4.45 & 8.65 & 10.67 & -21.30 & -10.75 & -1.45 & -1.95 \\
Scenario 10 & -6.90 & 3.10 & 0.17 & -1.25 & -1.22 & 0.20 \\
\hline
\end{tabular}

${ }^{*} 1 \mathrm{psi}=6,895 \mathrm{kPa}$.

TABle 8: Deck dead load stresses (psi*).

\begin{tabular}{|c|c|c|c|c|c|c|c|c|}
\hline \multicolumn{9}{|c|}{ Top fiber dead load stresses_-south } \\
\hline West abut & Midspan (45) & Pier $1(46)$ & Midspan (47) & Pier $2(48)$ & Midspan (49) & Pier $3(50)$ & Midspan (51) & East abut \\
\hline 0 & -436 & -466 & -773 & -430 & -760 & -379 & -428 & 0 \\
\hline \multicolumn{9}{|c|}{ Top fiber dead load stresses_-north } \\
\hline East abut & Midspan (44) & Pier 3 (43) & Midspan (42) & Pier $2(41)$ & Midspan (40) & Pier 1 (39) & Midspan (38) & West abut \\
\hline 0 & -428 & -379 & -760 & -430 & -773 & -466 & -436 & 0 \\
\hline
\end{tabular}

TABLE 9: Total stresses based on deflection measurements—south (psi*).

\begin{tabular}{lccccccc}
\hline Scenarios & Midspan (45) & Pier 1 (46) & Midspan (47) & Pier 2 (48) & Midspan (49) & Pier 3 (50) & Midspan (51) \\
\hline Scenario 1 & -390 & -426 & -806 & -418 & -751 & -388 & -478 \\
Scenario 2 & -623 & -626 & -801 & -440 & -771 & -389 & -444 \\
Scenario 3 & -576 & -586 & -792 & -437 & -817 & -433 & -434 \\
Scenario 4 & -343 & -387 & -767 & -428 & -755 & -384 & -491 \\
Scenario 5 & -366 & -407 & -779 & -432 & -766 & -384 & -438 \\
Scenario 6 & -436 & -466 & -830 & -409 & -755 & -383 & -395 \\
Scenario 7 & -436 & -466 & -773 & -430 & -796 & -359 \\
Scenario 8 & -529 & -546 & -758 & -425 & -740 & -458 \\
Scenario 9 & -390 & -426 & -824 & -448 & -768 & -386 & -451 \\
Scenario 10 & -532 & -385 & -764 & -433 & -762 & -377 & -391 \\
\hline
\end{tabular}

${ }^{*} 1 \mathrm{psi}=6,895 \mathrm{kPa}$. 
TABLE 10: Total stresses based on deflection measurements—north (psi*).

\begin{tabular}{lccccccc}
\hline Scenarios & Midspan (38) & Pier 1 (39) & Midspan (40) & Pier 2 (41) & Midspan (42) & Pier 3 (43) & Midspan (44) \\
\hline Scenario 1 & -390 & -466 & -773 & -430 & -760 & -435 & -494 \\
Scenario 2 & -250 & -503 & -811 & -455 & -828 & -401 & -454 \\
Scenario 3 & -623 & -485 & -792 & -434 & -773 & -438 & -498 \\
Scenario 4 & -296 & -439 & -801 & -442 & -726 & -470 & -298 \\
Scenario 5 & -390 & -463 & -776 & -432 & -755 & -387 & -418 \\
Scenario 6 & -436 & -475 & -782 & -409 & -819 & -347 & -391 \\
Scenario 7 & -390 & -471 & -777 & -434 & -772 & -356 & -401 \\
Scenario 8 & -669 & -460 & -766 & -437 & -741 & -370 & -438 \\
Scenario 9 & -436 & -409 & -832 & -426 & -750 & -398 \\
Scenario 10 & -579 & -481 & -757 & -431 & & -405 \\
\hline
\end{tabular}

${ }^{*} 1 \mathrm{psi}=6,895 \mathrm{kPa}$.

TABLE 11: Total stresses based on sensor readings_-south (psi*).

\begin{tabular}{|c|c|c|c|c|c|c|c|}
\hline Scenarios & Midspan (45) & Pier 1 (46) & Midspan (47) & Pier 2 (48) & Midspan (49) & Pier $3(50)$ & Midspan (51) \\
\hline Scenario 1 & -435 & -455 & -785 & -423 & -755 & -386 & -428 \\
\hline Scenario 2 & -435 & -468 & -770 & -429 & -750 & -393 & -428 \\
\hline Scenario 3 & -434 & -465 & -771 & -418 & -784 & -370 & -425 \\
\hline Scenario 4 & -433 & -454 & -775 & -418 & -757 & -380 & -428 \\
\hline Scenario 5 & -439 & -468 & -773 & -430 & -760 & -380 & -428 \\
\hline Scenario 6 & -436 & -460 & -787 & -408 & -764 & -368 & -428 \\
\hline Scenario 7 & -435 & -466 & -774 & -419 & -791 & -374 & -427 \\
\hline Scenario 8 & -442 & -466 & -772 & -431 & -759 & -376 & -425 \\
\hline Scenario 9 & -433 & -468 & -757 & -451 & -765 & -375 & -430 \\
\hline Scenario 10 & -445 & -468 & -773 & -430 & -759 & -380 & -428 \\
\hline
\end{tabular}

${ }^{*} 1 \mathrm{psi}=6,895 \mathrm{kPa}$.

scenarios were well under the maximum allowable limits. The stress values derived from the strains acquired from the sensor network were compared to those derived from the measured deflections at every location and every scenario. An example comparison of stresses due to live loads for the south deck panels under scenario 1 is illustrated in Figure 7. Such a comparison leads to the following observations:

(i) live load stresses at the deck top fiber are consistently small (both compression and tension stresses are less than 50 psi for scenario 1). In general, stresses due to live load are relatively smaller than stresses due to dead load;

(ii) for a given location in testing scenario 1, the deflection-derived results and sensor-derived results are consistent from the perspective of whether the top-fiber stress is in compression or tension;

(iii) at a given location under a specific testing scenario, the deck-panel top-fiber stresses derived from the sensor readings are consistently smaller than the stresses derived from deflection measurements;

(iv) the stress distribution reveals compression on top fiber (positive moment) at the midspan location where the truck load was located in testing scenario 1 and tension on top fiber (negative moment) at the neighboring pier location. The stresses of the midpoints of nearby spans and pier locations are consistent with the loading configuration.

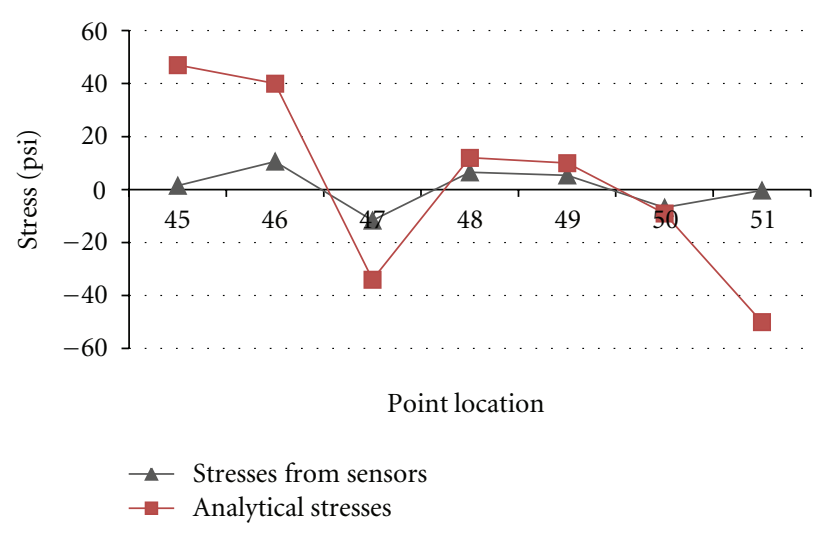

Figure 7: Comparison of analytical stresses and sensor stressessouth panels in testing scenario 1 .

These comparisons were conducted for all 10 scenarios. It was observed from both sets of results that top fiber stresses due to live load are relatively small when compared to the stresses caused by dead loads and temperature variation. However, the difference between the two sets of calculated stresses is significant, considering the small stress values. Stress values derived from deflection measurements are consistently larger than those derived from sensor readings. Also, the stress types (tension/compression) derived from the deflection measurements do not always match those derived 
TABLE 12: Total stresses based on sensor readings—north (psi*).

\begin{tabular}{lccccccc}
\hline Scenarios & Midspan (38) & Pier 1 (39) & Midspan (40) & Pier 2 (41) & Midspan (42) & Pier 3 (43) & Midspan (44) \\
\hline Scenario 1 & -426 & -370 & -769 & -425 & -768 & -467 & -436 \\
Scenario 2 & -426 & -381 & -758 & -429 & -758 & -486 & -461 \\
Scenario 3 & -426 & -378 & -756 & -419 & -784 & -46 \\
Scenario 4 & -424 & -360 & -786 & -412 & -769 & -466 \\
Scenario 5 & -431 & -380 & -760 & -431 & -772 & -466 & -436 \\
Scenario 6 & -428 & -375 & -767 & -408 & -799 & -449 & -436 \\
Scenario 7 & -426 & -374 & -771 & -418 & -777 & -466 \\
Scenario 8 & -434 & -379 & -761 & -431 & -774 & -434 \\
Scenario 9 & -424 & -370 & -749 & -451 & -784 & -463 & -433 \\
Scenario 10 & -435 & -376 & -760 & -431 & -774 & -468 & -436 \\
\hline
\end{tabular}

$* 1 \mathrm{psi}=6,895 \mathrm{kPa}$.

from sensor readings. In other words, some locations may have compression strains based on deflection measurements when the sensors are reading tension strains. These differences may be explained as follows:

(i) the current practice of the analytical methods in calculating stresses is conservative, which confirms the reality that bridges perform better than what theoretical methods predict;

(ii) the conservative assumptions used for computing stresses from deflections, namely using simply supported span moments when the bridge is continuously supported over four spans, result in large computed stresses;

(iii) the surface deflection measures include effects of compression in bearings, slack in component fit, shear deformation, and pier/pile/cap deformations, leading to a larger surface deflection than that of the concrete deck itself;

(iv) the bridge has a 3 -inch flexible asphalt overlay on top of the concrete deck panels, possibly resulting in larger surface deflections than what the concrete deck is actually experiencing;

(v) even though the surveying equipment can reach an accuracy of 0.0012 inch $(0.003048 \mathrm{~cm})$, the human error cannot be eliminated with methods used. That is, any measured deflections less than 0.01 inch $(0.0254 \mathrm{~cm})$ may be considered inaccurate due to the difficulty of eliminating human errors in reading the targets or holding the rod vertically. Therefore, it is believed that sensors provide much more accurate results than the optical survey instrument and whenever possible, sensors, instead of optical survey instrument, shall be used in bridge load testing;

(vi) sensors are not located at the top fiber (18 inches $(45.72 \mathrm{~cm})$ from the neutral access of the composite section). Rather, they are 2.5 inches $(6.35 \mathrm{~cm})$ below the surface (due to protective-cover requirements) or 15.5 inches (39.37) from the neutral access, resulting in a slightly smaller stress than would exist at the top fiber. Sensor readings and resulting stresses could be adjusted to accommodate this situation and perhaps reduce the differences, but they will remain different.

Advanced deflection-measuring instruments and techniques may eliminate some of the human error, but at a premium cost. In our case, however, since the sensors already existed for the purpose of monitoring the health of the bridge deck, they provided a low-cost, accurate, and quick alternative to the deflection measurement load testing method. Additionally, with sensors installed throughout the bridge, a stress surface can be constructed to provide a complete view of the bridge structure's response to varying loading scenarios, a feature that is difficult to achieve using conventional surveying methods. Therefore, this study concludes that embedded sensors provide a more accurate and precise measuring alternative to measuring the structural response of bridges under various loads.

\section{Acknowledgments}

The authors are grateful to the Michigan Department of Transportation (MDOT) for funding this study through MDOT Contract no. 04-0090/Z3. Any opinions, findings, conclusions, or recommendations expressed in this paper are those of the authors and do not necessarily reflect the views of MDOT or Western Michigan University.

\section{References}

[1] Federal Highway Administration (FHWA), "FHWA Bridge Programs NBI Data," 2008, http://www.fhwa.dot.gov/bridge/ defbr07.cfm.

[2] H. A. Capers and M. M. Valeo, "FHWA's international scan on ensuring bridge safety and serviceability," Transportation Research Record, no. 2202, pp. 117-123, 2010.

[3] Federal Highway Administration (FHWA), Bridge Preservation Guide, Maintaining a State of Good Repair Using Cost Effective Investment Strategies, FHWA, 2011.

[4] D. M. Frangopol, A. Strauss, and S. Kim, "Bridge reliability assessment based on monitoring," Journal of Bridge Engineering, vol. 13, no. 3, pp. 258-270, 2008.

[5] W.-W. Wang, J.-G. Dai, G. Li, and C.-K. Huang, "Long-term behavior of prestressed old-new concrete composite beams," Journal of Bridge Engineering, vol. 16, no. 2, pp. 275-285, 2011. 
[6] O. Abudayyeh, H. Cai, B. Mellema, and S. Yehia, "Quantifying time and user cost savings for rapid bridge construction technique," Transportation Research Record, no. 2151, pp. 1120, 2010.

[7] NCHRP-234, "Manual for Bridge Rating Through Loadtesting," National Cooperative Highway Research Program, Research Results Digest, Number 234, Transportation Research Board, Washington, DC, USA, 1998.

[8] AASHTO, Manual for Condition Evaluation of Bridges, Washington, DC, USA, AASHTO, 2nd edition, 2000.

[9] B. Phares, T. Wipf, L. Greimann, and Y. Lee, "Health Monitoring of Bridge Structures and Components Using SmartStructure Technology," Tech. Rep. 0092-04-14, Wisconsin Highway Research Program, 2005.

[10] D. D. Kleinhans, J. J. Myers, and A. Nanni, "Assessment of load transfer and load distribution in bridges utilizing FRP panels," Journal of Composites for Construction, vol. 11, no. 5, pp. 545$552,2007$.

[11] T. Hou and P. J. Lynch, "Rapid-to-deploy wireless monitoring systems for static and dynamic load-testing of bridges: validation on the grove street bridge," in 13th Annual International Symposium on Smart Structures and Materials, Proceedings of SPIE, San Diego, Calif, USA, February 2006.

[12] PCI, Bridge Design Manual, Precast/Prestressed Concrete Institute, Chicago, Ill, USA, 2003. 

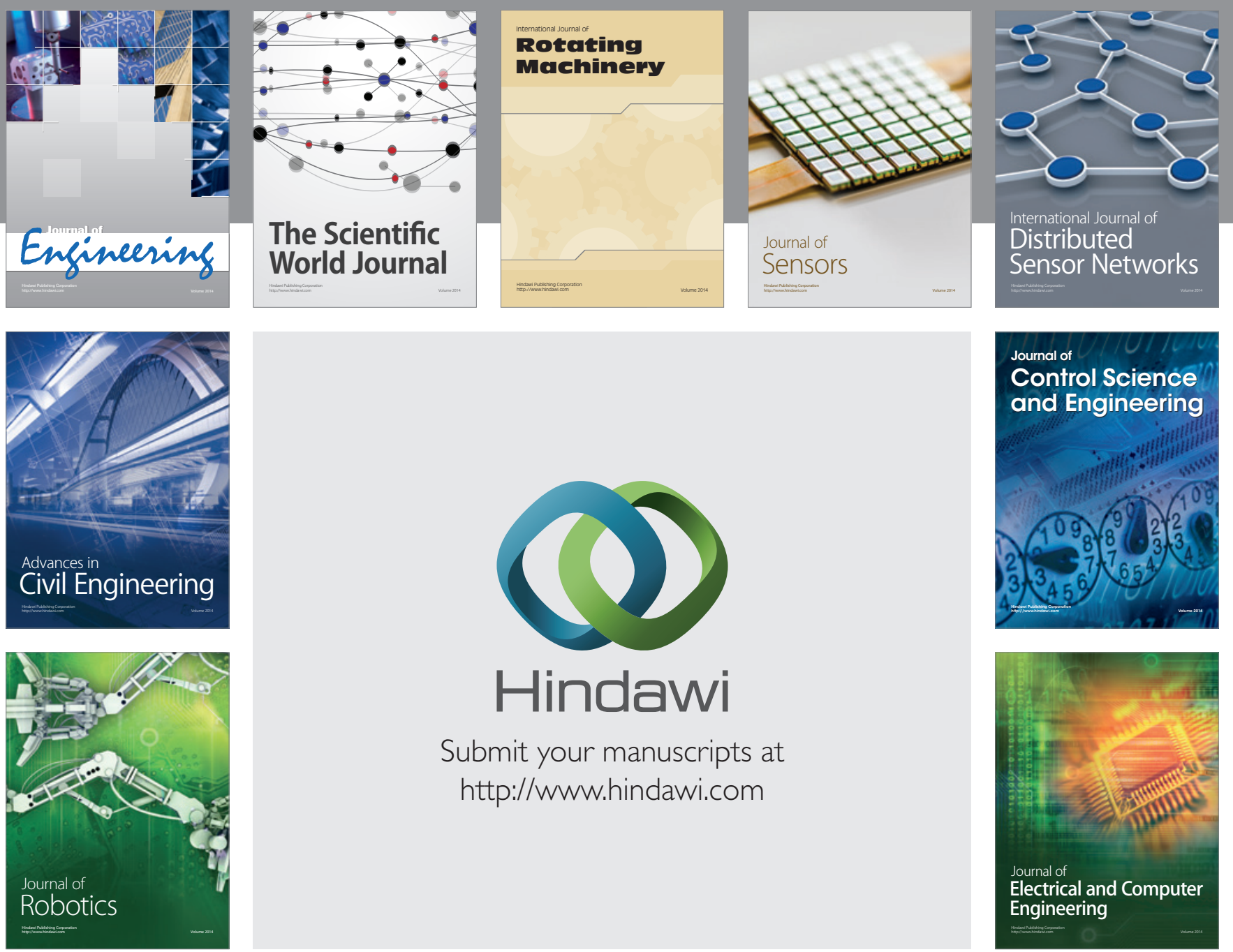

Submit your manuscripts at

http://www.hindawi.com
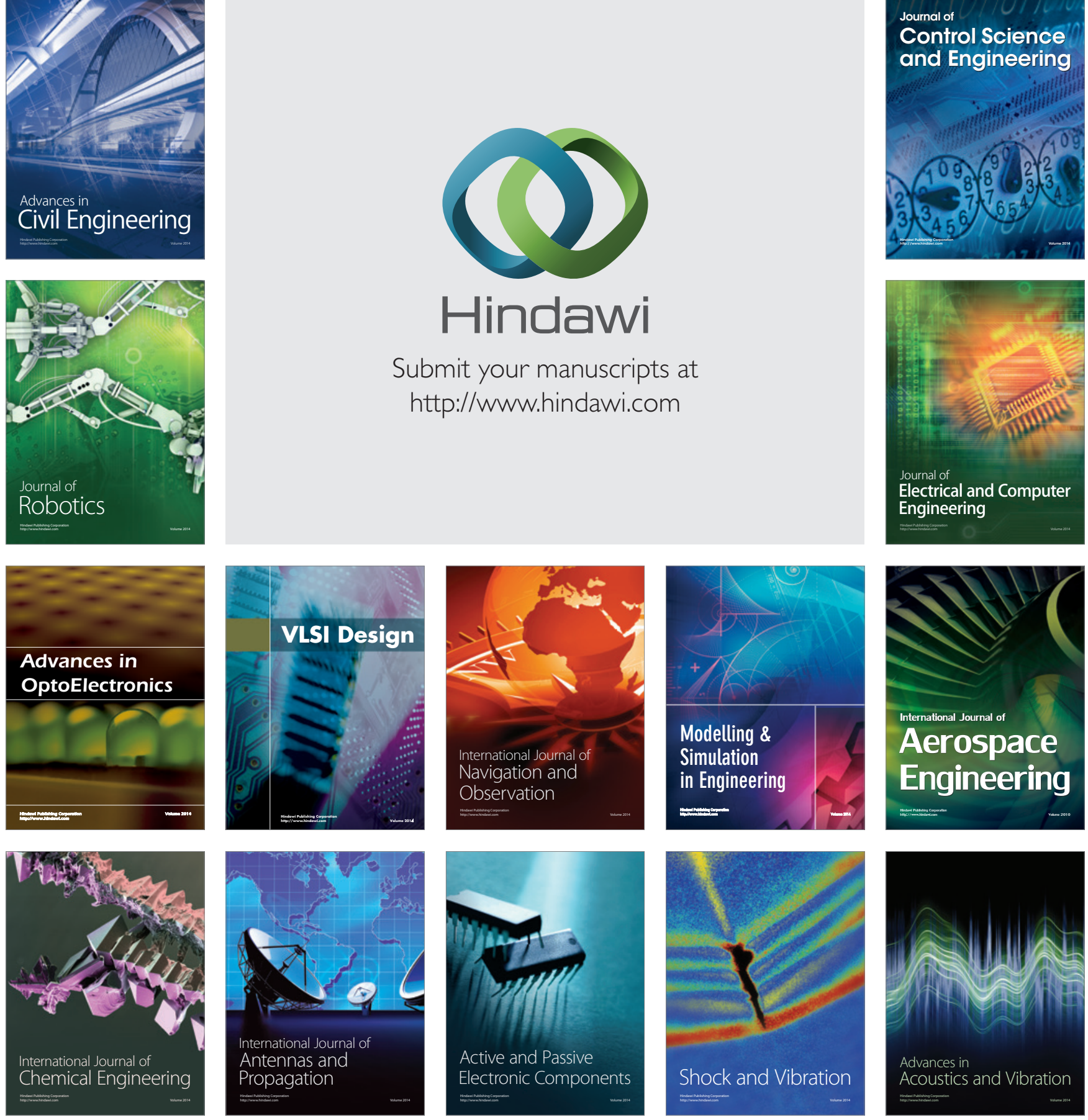